\title{
Traumatic Aortocaval Fistula Mimicking Undifferentiated Cardiomyopathy
}

\author{
Svetlana Gudkova ${ }^{1 *}$, Dmitry Duplyakov ${ }^{1,2}$, Alia Tukhbatova1 and Sergey Khokhlunov ${ }^{1,2}$ \\ ${ }^{1}$ Samara Regional Cardiology Clinic, Russia \\ ${ }^{2}$ Samara State Medical University, Russia
}

Submission: March 30, 2018; Published: June 25, 2018

*Corresponding author: Svetlana Gudkova, Samara Regional Cardiology Clinic, 43 Aerodromnaya St., Samara, 443070, Russian Federation, Russia, Tel: +79879709277; Email: gudkova63@gmail.com

Abstract

Spontaneous rupture or erosion of an abdominal aortic aneurysm into inferior vena cava (IVC) is the most common cause of aortocaval fistula (ACF). In rare cases ACFs are the result of penetrating or iatrogenic trauma. We report a unique case of a 32-year old man with chronic heart failure (CHF) with suspected dilated cardiomyopathy after previous myocarditis. Conservative treatment was not effective in reducing clinical symptoms. The patient had an abdominal stab wound 1 year earlier. The diagnosis of ACF between the right common iliac artery (RCIA) and IVC was confirmed by CT angiography. He successfully underwent surgical repair of his ACF with reduction of symptoms.

Keywords: Aortocaval fistula; Surgery; CT angiography

Abbreviations: IVC: Inferior Vena Cava; ACF: Aortocaval Fistula; CHF: Chronic Heart Failure; RCIA: Right Common Iliac Artery; PASP: Pulmonary Artery Systolic Pressure; IVC: Inferior Vena Cava

\section{Introduction}

Aortocaval fistula (ACF) is a rare clinical entity characterized by abnormal shunting of arterial blood into the venous system. In most cases it occurs after perforation of an aortic aneurysm into the veins (80-90\%), while in $10-20 \%$ of the cases it develops due to penetrating wounds of the abdomen, either traumatic or iatrogenic [1]. The clinical symptoms vary from totally asymptomatic to severe heart failures which depend on the size of ACF, diameter of artery and vein involved, the proximity to the heart, the age of the patient, etc. [2]. Usually, it requires surgical closure by open or endovascular intervention.

\section{Case Presentation}

A 32-year-old man had a history of surgical treatment due to penetrating abdominal stab wounds in February 2014. He noted mild dyspnea on exertion in June 2014, then mild leg edema appeared in September 2014. An echo exam revealed cardiomegaly with mild hydro pericardium at that time, and sub acute myocarditis was suspected. However, despite treatment severe deterioration of his exercise tolerance was observed and leg edema worsened.

He was admitted to our Hospital in November 2015 with shortness of breath on minimal exertion. The breath sounds were diminished, but no rales were heard on auscultation. The patient had regular rhythm with $\mathrm{HR}$ of $90 \mathrm{bpm}$, BP of 130 and $80 \mathrm{~mm} \mathrm{Hg}$ and with 18 respirations per minute. The abdomen was soft, but enlarged due to ascites; the liver was also enlarged. Severe leg edema was present. The remainder of the physical examination showed no abnormalities.

ECG was normal. Echocardiography showed moderate LV dilatation (LVED 67mm) with normal EF (LVEF 72\%), dilatation of the right ventricle $(47 \mathrm{~mm})$, moderate pulmonary artery hypertension with pulmonary artery systolic pressure (PASP) of $52 \mathrm{~mm} \mathrm{Hg}$ and severe tricuspid regurgitation. The inferior vena cava diameter (IVC) was $51 \mathrm{~mm}$ without any reaction on deep inspiration.

The laboratory data showed marked hyperbilirubinemia $(55 \mu \mathrm{mol} / \mathrm{l})$, ALT $(18 \mathrm{U} / \mathrm{l})$, AST $(21 \mathrm{U} / \mathrm{l})$, increased BNP level up to $855 \mathrm{pg} / \mathrm{ml}$, minor proteinuria, while markers of viral hepatitis and HIV were negative.

Abdominal drainage was performed with a daily evacuation of up to $1500 \mathrm{ml}$. Cardiac MRI revealed no pathological signals or perfusion defects. Findings of abdominal CT, cytological examination of ascetic fluid, and fibro colonoscopy were all normal and that allowed us to exclude oncological causes of ascites. Bearing in mind the history of the abdominal stab wound, 
normal LVEF, and signs of heart failure, mainly due to the right heart, examination of IVC was recommended. An aorto-caval fistula (ACF) between the right common iliac artery (RCIA) and IVC was revealed by CT angiography (Figure 1A \& 1B). The patient successfully underwent repair of his ACF with a synthetic patch to close the defect of aorta and RCIA (Figure 1C \& 1D).
Echocardiography showed significant reduction of IVC (24mm), RV (38mm), tricuspid regurgitation (mild) and SPAP $(34 \mathrm{mmHg})$ within a week postoperatively. CT angiography did not reveal an ACF during the arterial contrast phase (Figure 1E). The patch was visualized on the anterolateral wall of the RCIA and aorta (Figure 1F).

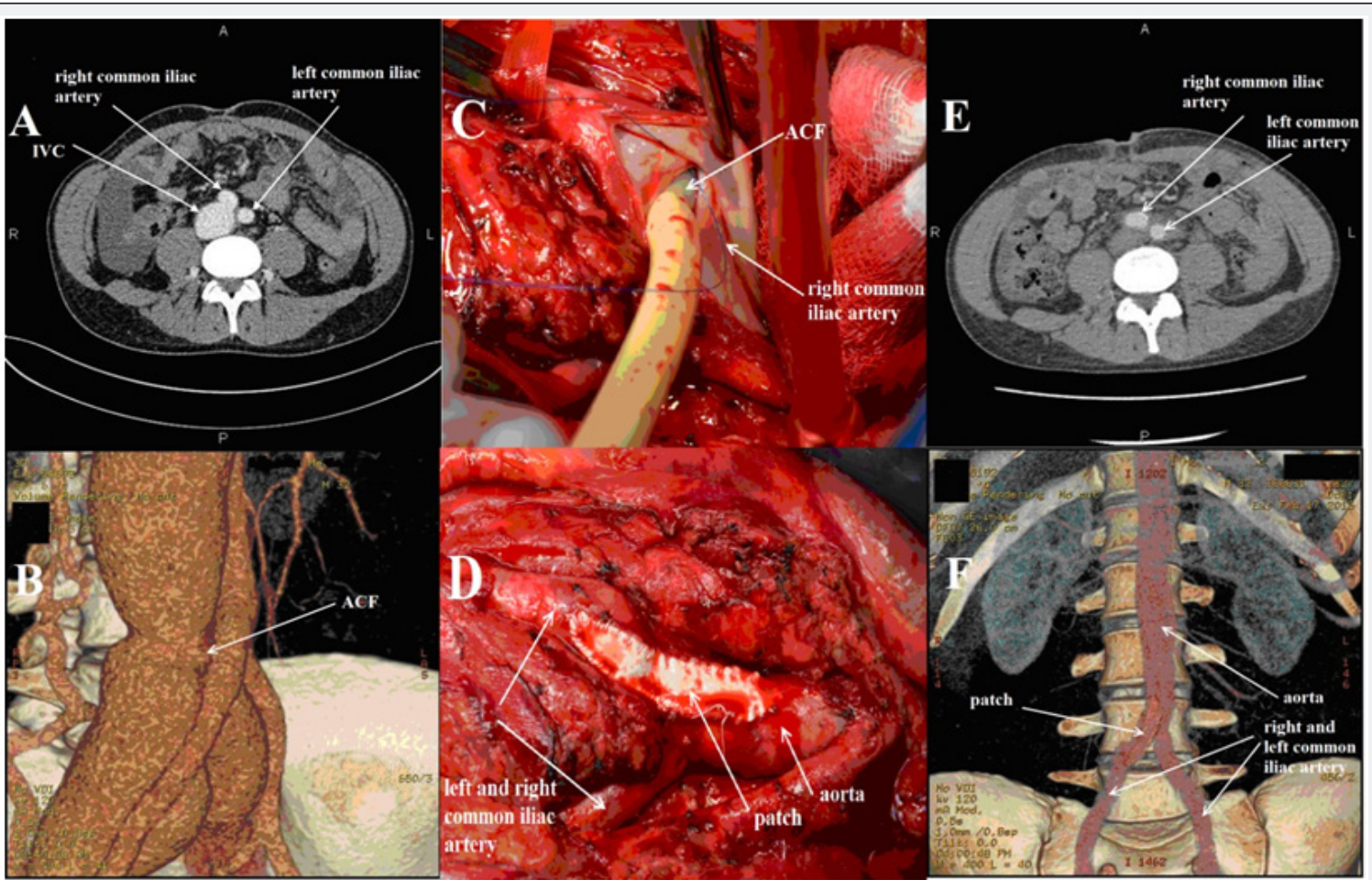

Figure 1A: CT angiography shows an ACF between the RCIA and IVC;

1B: $3 D$ reconstruction of an $A C F$ between posterior wall of the RCIA and IVC;

1C: Closure of the fistula from the lumen of the RCIA;

1D: Repair of the aorta and RCIA with a synthetic patch;

1E: CT angiography after repair (absence of contrast in IVC during the arterial phase);

1F: 3D angiography -the patch on the aorta and RCIA after repair.

\section{Discussion}

Traumatic ACF is a life-threatening complication of penetrating abdominal wounds. Most patients with ACF die at the scene of injury. Mortality in the acute phase is around $40-45 \%$ due to a combination of traumatic factors, the difficulty of getting the vessel exposure during surgery and intra operative bleeding [1].

Those patients who successfully survive the acute period may refer for help within months or even years after injury. Young patients without cardiac diseases are more likely to adapt to those hemodynamic changes that develop due to ACF. Our 32-year-old patient showed symptoms and signs of congestive heart failure and the development of cardiomegaly later on within roughly a year after penetrating abdominal stab wounds.

The classic ACF triad includes abdominal pain, palpable pulsatile abdominal mass and machinery-like abdominal bruit. Small fistulas may be asymptomatic. Large ACFs are characterized by left-right shunting, causing increased venous return and the development of edema of the lower extremities, hepatomegaly, ascites, portal hypertension and heart failure. Renal failure may occur in some patients due to hypo perfusion of kidneys [3].

Among non-invasive techniques MRI or CT angiography are considered as the gold standard for the imaging of ACFs and other pathology of aorta [4]. Timely surgical treatment, as a rule, leads to the regression of clinical symptoms.

\section{Author Contribution Statements}

Svetlana Gudkova and Alia Tukhbatova collected data and investigations. Svetlana Gudkova and Dmitry Duplyakov wrote the manuscript. Sergey Khokhlunov supervised the whole work. All authors were involved in the treatment of the patient and contributed to the final manuscript.

\section{Acknowledgment}

The authors would like to thank Prof. Olga Moiseeva (Federal North-West Medical Research Center, Saint-Petersburg) for her contribution to the care taken of this patient. 


\section{References}

1. Feliciano DV, Burch JM, Graham JM (1996) Abdominal vascular injury In: Feliciano DV, Moore EE, Mattox KL, (Eds.), Trauma, Appleton \& Lange, Norwalk (CT), USA, p. 615.

2. Spencer TA, Smyth SH, Wittich G, Hunter GC (2006) Delayed presentation of traumatic aortocaval fistula: A report of two cases and a review of the associated compensatory hemodynamic and structural changes. J Vasc Surg 43(4): 836-840.
3. Bhatia M, Platon A, Khabiri E, Becker C, Poletti P (2010) Contrast enhanced ultrasonography versus MR angiography in aortocaval fistula: case report. Abdom Imaging 35(3): 376-380.

4. Kim H, Randolph S (2012) Traumatic aortocaval fistula from gunshot wound, complicated by bullet embolization to the right ventricle. Radiol Case Rep 7(4): 767.

\section{Your next submission with Juniper Publishers} will reach you the below assets

- Quality Editorial service

- Swift Peer Review

- Reprints availability

- E-prints Service

- Manuscript Podcast for convenient understanding

- Global attainment for your research

- Manuscript accessibility in different formats

( Pdf, E-pub, Full Text, Audio)

- Unceasing customer service

Track the below URL for one-step submission https://juniperpublishers.com/online-submission.php 